\title{
Posterior Fossa Tumours in Pediatrics; Retrospective Study of the MRI Features
}

\author{
MAHMOUD A. DAWOOD, M.D.; NOHA M. ABDEL MABOUD, M.D.; HAYTHAM H. EL-SAEED, M.D.; \\ MAHA A. SHAWKY, M.D. and EHAB E. ELGAMAL, M.D.
}

The Department of Radiology \& Neurosurgery, College of Medicine, Tanta University, Tanta, Egypt

\begin{abstract}
Background: Posterior fossa tumours is one of the most common tumours in pediatrics. The most common tumours include juvenile pilocytic astrocytoma. Differential diagnosis of pediatric brain tumours begins with accurate localization of the site of origin the tumours, which is the most important diagnostic features, Conventional MRI with contrast study remains the gold standard for evaluation of brain tumours.
\end{abstract}

Aim of Study: Is to assess role of MRI in evaluation of space occupying lesions seen at the posterior fossa in pediatric age group.

Patients and Methods: This retrospective study, including 40 children with their age ranging between 2 and 10 years. All the forty patients were examined by; axial T1 WI, axial T2 WI, coronal and axial FLAIR, post contrast T1WI was done after injection of Magnevist $(0.1 \mathrm{ml} / \mathrm{Kg})$; DW images and $\mathrm{ADC}$ maps were acquired.

Results: MRI study revealed 16 cases diagnosed as medulloblastoma (40\%), 8 cases as Ependymoma $(20 \%), 8$ cases as juvenile pilocytic astrocytoma (20\%), 6 cases as pontine Glioma (15\%) and 2 cases as Schwannoma (5\%).

Conclusion: Conventional MRI with DWI \& ADC has high accuracy in the differentiation of posterior fossa tumours in pediatrics.

Key Words: Posterior fossa-Pediatric-MRI-Juvenile pilocytic astrocytoma - Medulloblastoma Ependymoma - Schwannoma-Brainstem glioma.

\section{Introduction}

POSTERIOR fossa tumours account for $45-60 \%$ of all pediatrics tumours, the most common tumours include juvenile pilocytic astrocytoma (JPA) which is the most common pediatric benign cerebellar neoplasm, medulloblastoma, ependymoma, and brain stem glioma are also common tumours $[\mathbf{1 , 2}]$, oligodendroglioma is a rare pediatric low grade, slowly growing cerebral hemispheric tumour and account for only about 1\% [3]. Medulloblastoma

Correspondence to: Dr. Mahmoud A. Dawood, The Department of Radiology \& Neurosurgery, College of Medicine, Tanta University, Tanta, Egypt is the most common malignant cerebellar tumours in pediatric, these tumours have aggressive course with tendency of CSF dissemination and fatal outcome [4]. Ependymoma is the third posterior fossa tumours and arising from the floor of the fourth ventricle with a peak incidence between 3 to 5 years [5]. Brainstem gliomas comprise approximately $10-20 \%$ of all intracranial tumors in children with age incidence less than 10 years [6] Differential diagnosis of pediatric brain tumours begins with accurate localization of the site of origin the tumours, which is the most important diagnostic features, Conventional MRI with contrast study remains the gold standard for evaluation of brain tumours, it helps in the assessment of location, and extent of the tumour, recent studies evaluated the role of diffusion weighted image in differentiating grade and type of pediatric brain tumours in the posterior fossa $[1,7,8]$

\section{Patients and Methods}

This retrospective study was conducted according to the guidelines of the ethics committee of Tanta university and was approved by our institutional review board; all child parents gave us written informed consent. This retrospective study was done between August 2015 and February 2017 including 40 children with their age ranging between 2 and 10 years, (mean $4 \pm 1$ ), 24 males $(60 \%)$ and 16 females (40\%). Complaining of headache, blurring of vision, squint, ataxia, cranial nerve palsy and symptoms of increased intracranial tension.

\section{Image protocol:}

All examinations were performed using a 1.5 T MR Unit (SIGNA Horizon, General Electric Medical System, Milwaukee, WI) using head coil.

Abbreviation:

JPA: Juvenile pilocytic astrocytoma. 


\section{MRI protocol:}

All the twenty patients were examined by; axial T1 WI (TR/TE: 400-600/10-20m/sec.), axial T2 WI (TR/TE: 2000-4000/ 100-120m/sec.), coronal and axial FLAIR (TR/TE/TI: 4000-6000/1 40/ $1200 \mathrm{~m} / \mathrm{sec}$.),post contrast T1WI was done after injection of Magnevist $(0.1 \mathrm{ml} / \mathrm{Kg})$; slice thickness: $5 \mathrm{~mm}$, the matrix was $256 \times 256$ and the field of view was $220-240 \mathrm{~mm}$.

Diffusion weighted imaging with apparent diffusion coefficient calculation:

DW images were obtained by using an axial echo-planar SE sequence, average, $5 \mathrm{~mm}$ section thickness. DW images and ADC maps were acquired by using $b$ values of 0 and $1000 \mathrm{~s} / \mathrm{mm}^{2}$. Post processing of ADC maps was performed. Standard mean ADC values were cąlculated automatically and expressed in $10-3 \mathrm{~mm} / \mathrm{sec}$.

Histopathology is our gold standard.

\section{Statistical analysis:}

Statistical analysis were undertaken to prove the efficacy of MRI \& diffusion in the evaluation of posterior fossa brain tumors. Statistical analysis were performed using the SPSS software package version 16.0 (statistical package for social science $\mathrm{TM}$ ) and $p<0.05$ was considered to be statistically significant. The sensitivity, specificity for each protocol were compared in order to evaluate the reliability of each of them \& when they are combined.

\section{Results}

In this retrospective study, forty patients (24 $(60 \%)$ male \& 16 ranged $(40 \%)$ females with their age ranges from 2 to 10 years), (Table 1, Figs. 1,2) have posterior fossa tumours with the postoperative pathological reports, was included in this study. The patients' complaint shown in Table (2) \& Fig. (3).

Table (1): Distribution of age and gender among the studied cases.

\begin{tabular}{cll}
\hline Characteristics & No. & $\%$ \\
\hline Age (years): & 2 & \\
$<1$ & 12 & 5 \\
$1-<5$ & 14 & 30 \\
$5-<10$ & 12 & 35 \\
$10-<15$ & 40 \\
\hline Total & 40 & 100 \\
Gender: & & \\
Male & 24 & 60 \\
Female & 16 & 40 \\
\hline Total & 40 & 100 \\
\hline
\end{tabular}

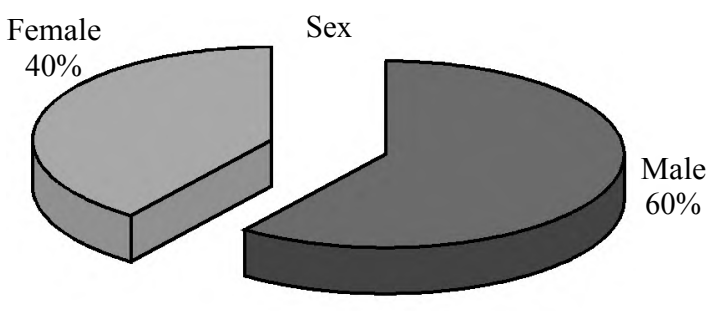

Fig. (1)

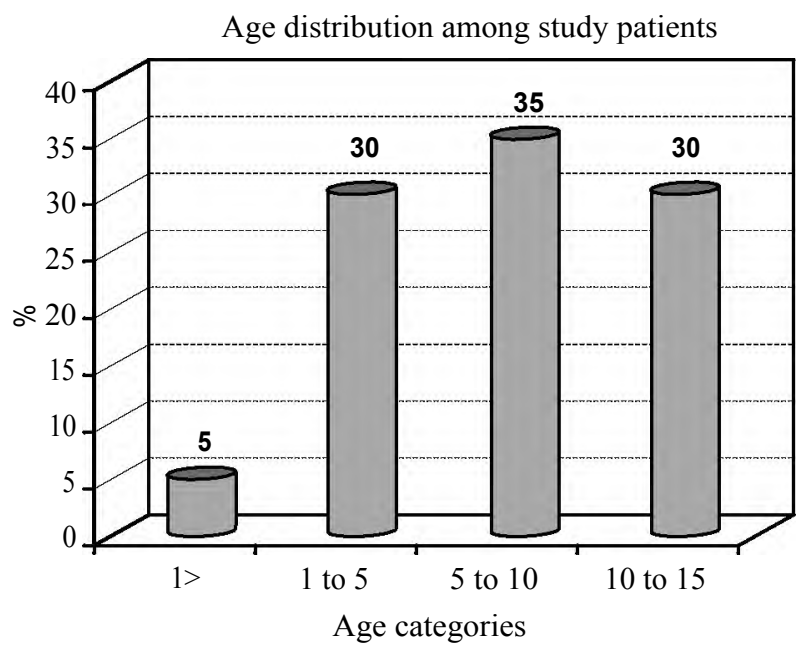

Fig. (2)

Table (2): Patients complains in the studied 20 patients.

\begin{tabular}{lcc}
\hline Complain & No. of patients & $\%$ \\
\hline Headache and vomiting & 30 & 75 \\
Visual complains & 10 & 25 \\
Ataxia & 2 & 5 \\
Increased head size & 2 & 5 \\
Hearing loss & 2 & 5 \\
\hline
\end{tabular}

N.B: More than one symptom could be present in the same patient.

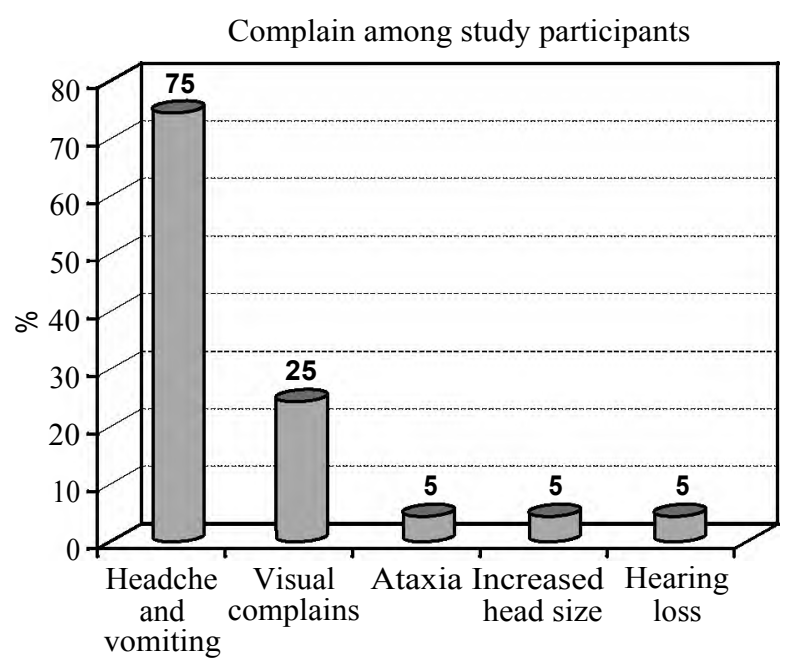

Fig. (3) 
MRI study revealed 16 cases diagnosed as medulloblastoma (40\%) (Cases 3,4$), 8$ cases as Ependymoma (20\%) (Case 6), 8 cases as juvenile

Table (3): MRI diagnosis of cases.

\begin{tabular}{lll}
\hline Diagnosis & No. & $\%$ \\
\hline Medulloblastoma & 16 & 40 \\
Ependymoma & 8 & 20 \\
JPA & 8 & 20 \\
Glioma & 6 & 15 \\
Schwannoma & 2 & 5 \\
& & \\
\hline Total & 40 & 100 \\
\hline
\end{tabular}

Other MRI findings noted in the studied group include; Hydrocephalus was the most common association especially in cases of medulloblastoma followed by cystic changes which were noted in all cases of juvenile pilocytic astrocytoma, hemorrhage and necrosis were also noted especially in cases of medulloblastoma (Table 4). pilocytic astrocytoma (20\%) (Case 5), 6 cases as pontine Glioma (15\%) (Cases 1,2) and 2 case as Schwannoma (5\%) (Case 7), (Table 3, Fig. 4).

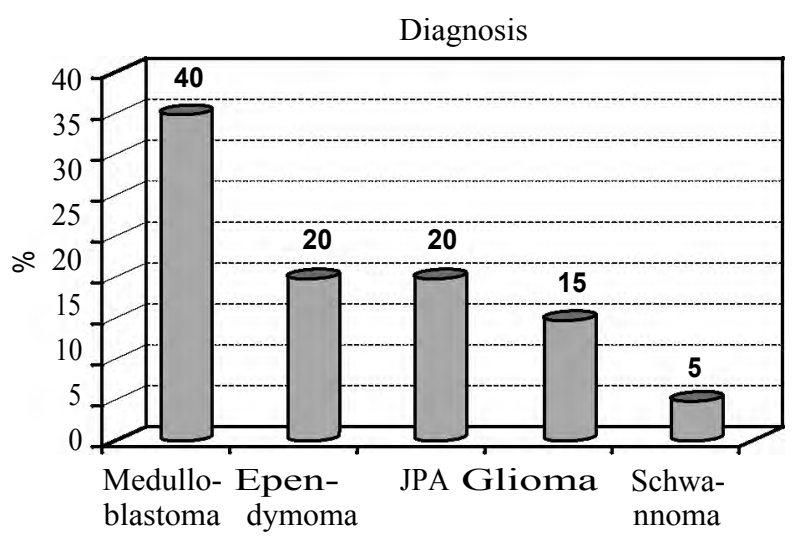

Fig. (4)

The signal intensities on MRI were low SI in T1 WI 28 cases $(70 \%), 4$ cases $(10 \%)$ showed intermediate SI and 4 cases (10\%) showed high SI, on T2 WI and FLAIR sequence 36 case $(90 \%)$ showed high SI while only 4 cases showed intermediate SI (Table 4 \& Fig. 5) \& (Table 5).

Table (4): Other MRI findings in the studied group.

\begin{tabular}{|c|c|c|c|c|c|c|}
\hline Diagnosis & $\begin{array}{l}\text { Medulloblastoma } \\
\qquad(\mathrm{n}=16)\end{array}$ & $\underset{(n=8)}{\text { Ependymoma }}$ & $\underset{(n=6)}{\text { Glioma }}$ & $\begin{array}{c}\text { JPA } \\
(\mathrm{n}=8)\end{array}$ & $\begin{array}{c}\text { Schwannoma } \\
(\mathrm{n}=2)\end{array}$ & Sig. test $p$ \\
\hline Necrosis & $2(12.5 \%)$ & $2(25 \%)$ & $2(33.3 \%)$ & & - & $\begin{array}{l}x^{2} \\
10.79 \\
\text { MC } \\
0.017^{*}\end{array}$ \\
\hline Hemorrhage & $6(37.5 \%)$ & & $233.3 \%)$ & & - & \\
\hline Cystic changes & $2(12.5 \%)$ & $2(25 \%)$ & $2(33.3 \%)$ & $8(100 \%)$ & - & \\
\hline Hydrocephalus & $10(62.5 \%)$ & $6(75 \%)$ & $2(33.3 \%)$ & $4(50 \%)$ & - & \\
\hline
\end{tabular}

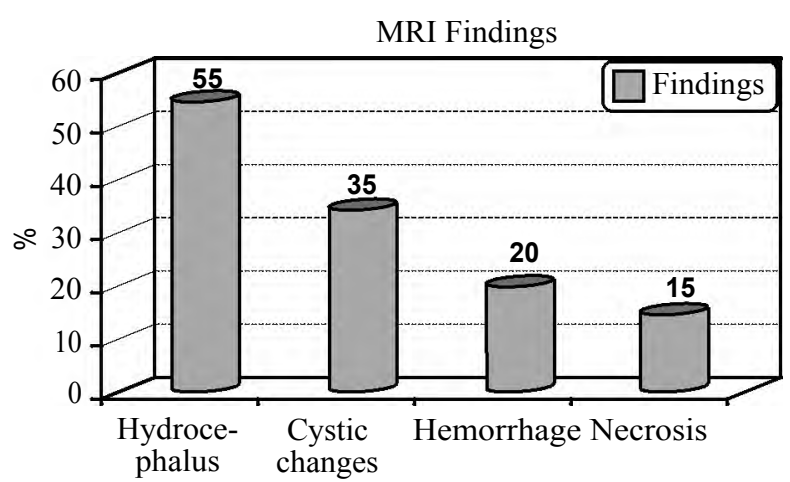

Fig. (5)

The pattern of enhancement after gadolinium injection shown in Table (6), there were, 24 patients $(60 \%)$ had heterogeneous enhancing lesion, 12 patients $(30 \%)$ had homogenously enhancing lesion,
Table (5): MRI signal intensity of the lesions.

\begin{tabular}{lccc}
\hline $\begin{array}{l}\text { MRI } \\
\text { sequence }\end{array}$ & Low SI & Intermediate & High \\
\hline T1 WI & $28(70 \%)$ & $4(10 \%)$ & $8(20 \%)$ \\
T2 WI & $4(10 \%)$ & $36(90 \%)$ \\
Flair & $4(10 \%)$ & $36(90 \%)$ \\
\hline
\end{tabular}

2 patient (5\%) had faint enhancing lesion and 2 patient (5\%) had non enhancing lesion. Diffusion Weighted Image and ADC map in all study patients were demonstrated in Table (7) \& Fig. (6). 
Table (6): Pattern of enhancement in all study patients.

\begin{tabular}{|c|c|c|c|c|c|c|c|}
\hline Diagnosis & $\begin{array}{l}\text { Medulloblastoma } \\
\qquad(\mathrm{n}=8)\end{array}$ & $\underset{(\mathrm{n}=4)}{\text { Ependymoma }}$ & $\underset{(n=3)}{\text { Glioma }}$ & $\begin{array}{c}\text { JPA } \\
(n=4)\end{array}$ & $\begin{array}{l}\text { Schwannoma } \\
(\mathrm{n}=1)\end{array}$ & $\begin{array}{l}\text { Sig. } \\
\text { test } p\end{array}$ & Diagnosis \\
\hline Heterogeneous & $12(75 \%)$ & $8(100 \%)$ & $2(33.3 \%)$ & $2(25 \%)$ & - & $\begin{array}{l}\chi^{2} \\
10.18 \\
9 \\
\mathrm{MC} \\
0.014^{*}\end{array}$ & Heterogeneous \\
\hline Homogenous & $4(25 \%)$ & & - & $6(75 \%)$ & $2(100 \%)$ & & Homogenous \\
\hline Faint & - & & $233.3 \%)$ & - & - & & Faint \\
\hline Non enhancing & - & & $2(33.3 \%)$ & - & - & & Non enhancing \\
\hline
\end{tabular}

Table (7): DWI and ADC map in different MRI diagnosis.

\begin{tabular}{lcccccc}
\hline Diagnosis & $\begin{array}{c}\text { Medulloblastoma } \\
(\mathrm{n}=16)\end{array}$ & $\begin{array}{c}\text { Ependymoma } \\
(\mathrm{n}=8)\end{array}$ & $\begin{array}{c}\text { Glioma } \\
(\mathrm{n}=6)\end{array}$ & $\begin{array}{c}\text { JPA } \\
(\mathrm{n}=8)\end{array}$ & $\begin{array}{c}\text { Schwannoma } \\
(\mathrm{n}=2)\end{array}$ & Sig. test $p$ \\
\hline $\begin{array}{l}\text { DWI: } \\
\text { Restricted }\end{array}$ & $16(100 \%)$ & & $2(33.3 \%)$ & & $\chi^{2}$ \\
Free & - & $8(100 \%)$ & $4(66.7 \%)$ & $8(100 \%)$ & $2(100 \%)$ & $\begin{array}{l}\text { MC } \\
0.014 *\end{array}$ \\
ADC map & & & & & $\mathrm{F} 18.73$ \\
Mean \pm S.D. & $0.75 \pm 0.46$ & $1.00 \pm 0.0$ & $1.33 \pm 0.58$ & $1.75 \pm 0.5$ & 1.0 & $p 001^{*}$ \\
\hline 2
\end{tabular}

$\chi^{2}$ : Chi square test. MC: Motecarlotest for chi square test. F: f for ANOVA test. $\quad$ *: Statistically significant.

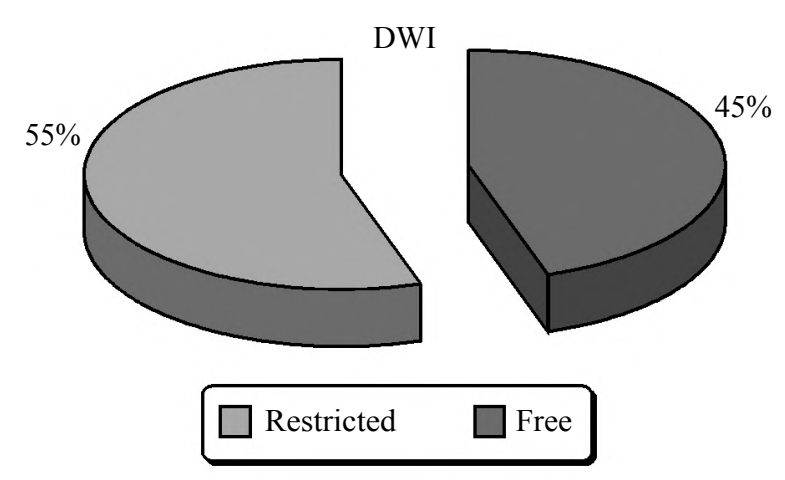

Fig. (6)

DWI was significantly restricted in cases of medulloblastoma with ADC value ranging from 0.5 to $0.8 \times 10^{-3} \mathrm{~mm}^{2} / \mathrm{s}$., in juvenile pilocytic astrocytoma the cystic component appeared hypointense on DWIs compared to normal appearing brain parenchyma, denoting free diffusion. Their ADC values ranged from $2.1-2.9 \times 10^{-3} \mathrm{~mm}^{2} / \mathrm{s}$. The solid mural nodule of the tumor displays iso-to hypointense signal on DWI (b1000) and iso to hyperintense signal on ADC map denoting free diffusion, the ADC value was between 1.4 and $1.9 \times 10^{-3}$ $\mathrm{mm}^{2} / \mathrm{s}$. In cases of ependymoma, the signal inten- sity was heterogeneous on both DWI and ADC map due to the presence of solid and cystic components. The solid enhanced component displayed iso-to slightly hyperintense signal on DWI, hypointense signal on ADC map and had ADC value between 1.01 and $1.3 \times 10^{-3} \mathrm{~mm}^{2} / \mathrm{s}$ suggesting restricted diffusion more than that seen in JPA cases. In brain stem Glioma the signal intensity was hypointense on DWI compared to normal brain parenchyma denoting free diffusion, one case show heterogeneous signal intensity in DWI and ADC map denoting high grade of anaplesia with $\mathrm{ADC}_{-3}$ value ranging from $1.1 \times 10^{-3}$ to $1.4 \times 10^{-3}$. In Schwannoma the signal intensity was hypointense on DWI and hyperintense on ADC map with ADC value $1.6 \times 10^{-3}$ denoting free diffusion. It also was found that lower ADC values were consistent with more malignant lesions as in medulloblastoma where higher ADC values were found in benign lesions as in Juvenile pilocytic astrocytoma. Table (8), Fig. (7) showed the distribution of patient characteristics according to MRI diagnosis. Table (9) revealed the Histopathological Diagnosis of patients: Tables $(10,11,12)$ demonstrated the comparison between MRI diagnosis and histopathological diagnosis. 
Table (8): Distribution of patient characteristics according to MRI diagnosis.

\begin{tabular}{|c|c|c|c|c|c|c|}
\hline Diagnosis & $\begin{array}{l}\text { Medulloblastoma } \\
\qquad(\mathrm{n}=16)\end{array}$ & $\underset{(n=8)}{\text { Ependymoma }}$ & $\begin{array}{c}\text { Glioma } \\
(n=6)\end{array}$ & $\begin{array}{l}\text { JPA } \\
(n=8)\end{array}$ & $\begin{array}{l}\text { Schwannoma } \\
\quad(n=2)\end{array}$ & Sig. test $p$ \\
\hline Age: & & & & & & Sample \\
\hline Mean \pm S.D. & $6.0 \pm 3.42$ & $5.17 \pm 5.15$ & $8.33 \pm 0.57$ & $11.5 \pm 1.29$ & 15 & median test \\
\hline Range & $4-14$ & $6.7-11$ & $8-9$ & $10-13$ & - & $0.26^{*}$ \\
\hline \multicolumn{7}{|l|}{ Sex: } \\
\hline Male & $6(37.5 \%)$ & $4(50 \%)$ & $6(100 \%)$ & $6(75 \%)$ & $2(100 \%)$ & $\chi^{2} 4.68$ \\
\hline Female & $10(62.5 \%)$ & $4(50 \%)$ & $0(0.0 \%)$ & $2(25 \%)$ & $0(0.0 \%)$ & MC 0.3 \\
\hline
\end{tabular}

Sex distribution according to diagnosis

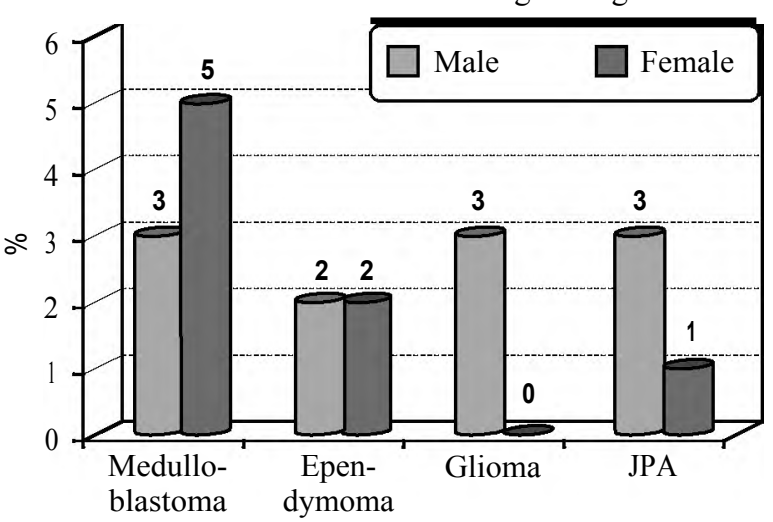

Fig. (7)
Table (9): Histopathological diagnosis of patients.

\begin{tabular}{lll}
\hline Diagnosis & No. & $\%$ \\
\hline Medulloblastoma: & & \\
$\quad$ Classic & 6 & 17.6 \\
$\quad$ Desmoplastic & 8 & 23.5 \\
$\quad$ Anaplastic & 2 & 5.8 \\
Ependymoma & 8 & 23.5 \\
Juvenile pilocytic astrocytoma & 6 & 17.6 \\
Schwannoma & 2 & 5.8 \\
Hemangioblastoma & 2 & 5.8 \\
\hline Total & 34 & 100 \\
\hline
\end{tabular}

Histopathology from 6 cases weren't available due to inoperable tumor and death of the patients.

Table (10): MRI diagnosis versus histopathological diagnosis.

\begin{tabular}{|c|c|c|c|c|c|c|}
\hline & \multicolumn{5}{|c|}{ MRI diagnosis } & \multirow[b]{2}{*}{$\begin{array}{l}\text { Sig. } \\
\text { test \& } p\end{array}$} \\
\hline & $\begin{array}{l}\text { Medulloblastoma } \\
\qquad(\mathrm{n}=16)\end{array}$ & $\underset{(n=8)}{\text { Ependymoma }}$ & $\begin{array}{c}\text { Glioma } \\
(\mathrm{n}=6)\end{array}$ & $\begin{array}{l}\text { Juvenile pilocytic } \\
\text { astrocytoma } \\
(\mathrm{n}=8)\end{array}$ & $\begin{array}{c}\text { Schwannoma } \\
(\mathrm{n}=2)\end{array}$ & \\
\hline \multirow[t]{2}{*}{ Histopathological } & $16(100 \%)$ & $\begin{array}{l}\text { Ependymoma } \\
8(100 \%)\end{array}$ & - & $6(75 \%) \mathrm{JPA}$ & $2(100 \%)$ & $\begin{array}{l}\chi^{2} \\
34.0\end{array}$ \\
\hline & & & & $\begin{array}{l}2(25 \%) \\
\text { hemangioblastoma }\end{array}$ & & $\begin{array}{l}\mathrm{MC} \\
0.001 *\end{array}$ \\
\hline
\end{tabular}

Table (11): Sensitivity of MRI in detection of posterior fossa tumors in comparison to histopathological diagnosis "the gold standard".

\begin{tabular}{ccccc}
\hline & \multicolumn{2}{c}{ Histopathological diagnosis } & Sensitivity \\
\cline { 2 - 4 } & Positive & Negative & Total & $\%$ \\
\hline $\begin{array}{c}\text { MR diagnosis: } \\
\text { Positive } \\
\text { Negative }\end{array}$ & 32 & 0 & 32 & $94.1 \%$ \\
\hline Total & 2 & 0 & 2 & \\
\hline
\end{tabular}

Table (12): Correlation between MRI diagnosis and histopathological diagnosis.

\begin{tabular}{lcc}
\hline & \multicolumn{2}{c}{ MRI diagnosis } \\
\cline { 2 - 3 } & $r$ & $p$ \\
\hline Histo-pathological & $0.914^{*}$ & $0.001 *$ \\
\hline$r:$ Correlation by spearman rank correlation. \\
*: Statistically significant. \\
Statistically significant positive strong correlation between \\
MRI diagnosis and histopathological confirmation
\end{tabular}




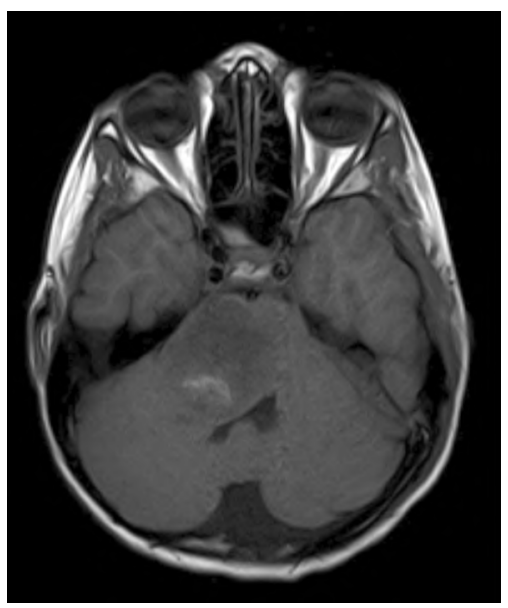

A- Axial T 1 WI.

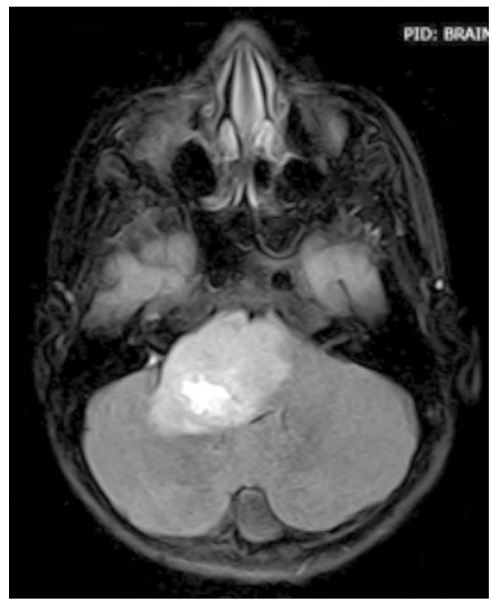

C- Axial FLAIR.

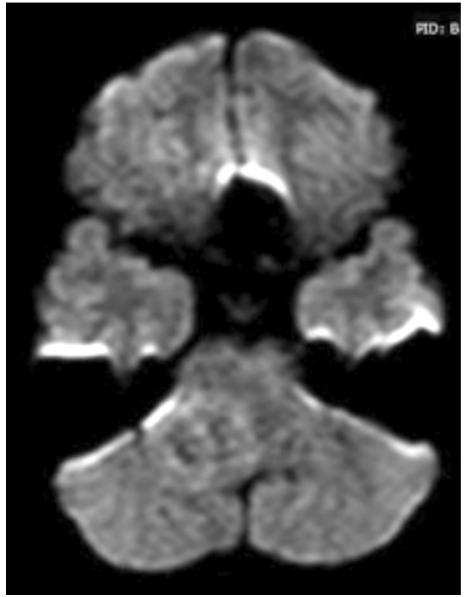

H- Diffusion WI.

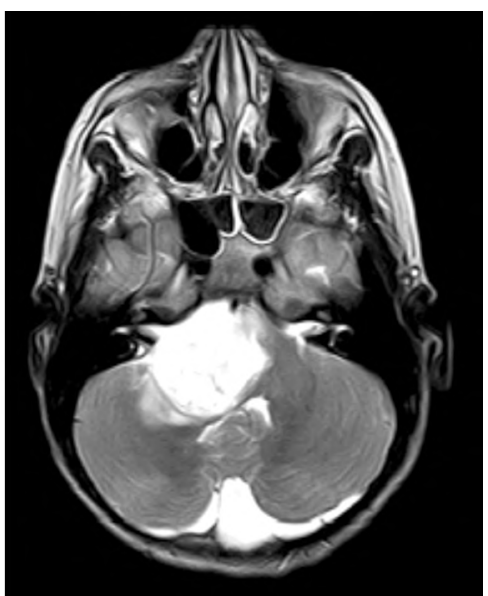

B- Axial T2WI.

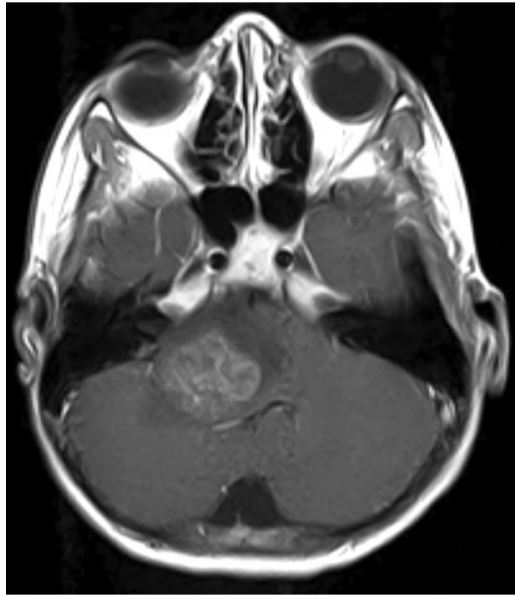

D- Axial T 1 WI+contrast.

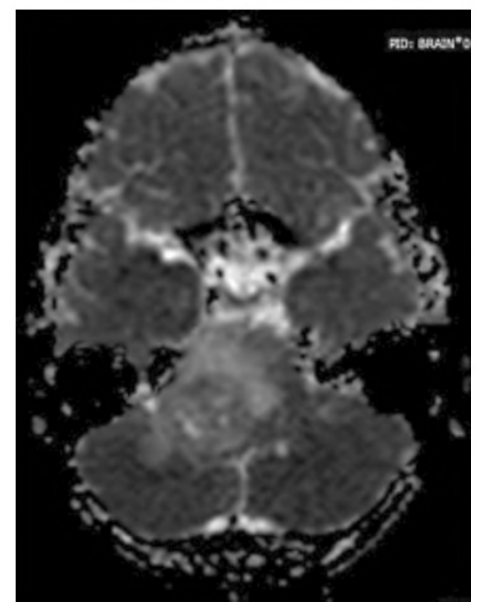

I- ADC image.

Fig. (7): Male patient aged 9 years old complaining of squint.

MRI: Large space occupying lesion involving most of pons (mainly to the right side) measures $4 \times 4.5 \times 5.5 \mathrm{~cm}$ displaying low signal intensity in T1WI with small areas of subacute hemorrhage within (A), high signal intensity in T2WI (B) and FLAIR (C) sequences with extrinsic cystic parts within, the mass show heterogeneous patchy contrast enhancement after IV contrast injection (D), the mass encroaching upon the right cerebello pontine cistern with mild compression and displacement of the fourth ventricle to the left side with no significant supra tentorial hydrocephalic changes. Picture is suggestive of pontine glioma with hemorrhagic component.

$D W I$ : The lesion show small areas of restricted diffusion. $(\mathrm{H})$.

$A D C$ values: Lesion measured $0.4 \times 10_{-3} \mathrm{~mm}^{2} / \mathrm{s}$ (I).

Perilesional edema: Measured $0.7 \times 10^{-3} \mathrm{~mm} / \mathrm{s}$. 


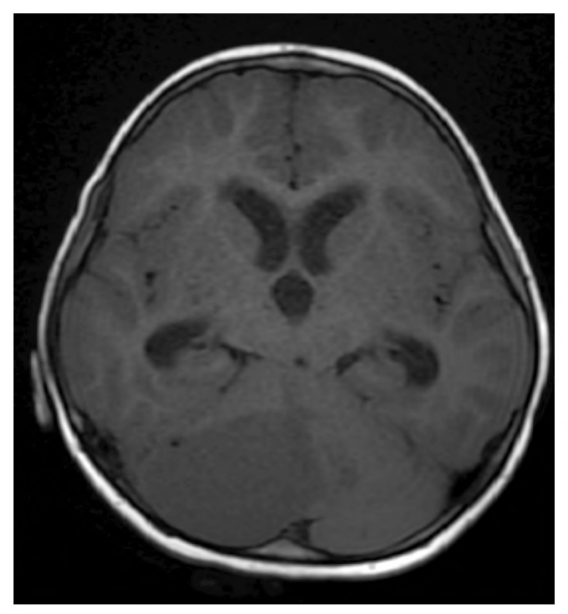

A- Axial T1WI.

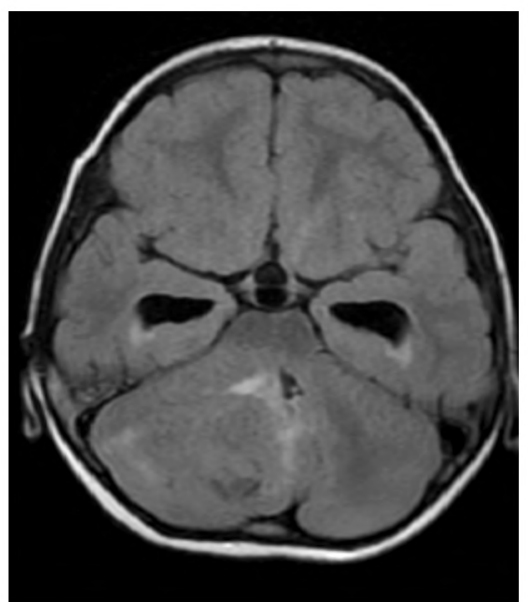

C- Axial FLAIR.

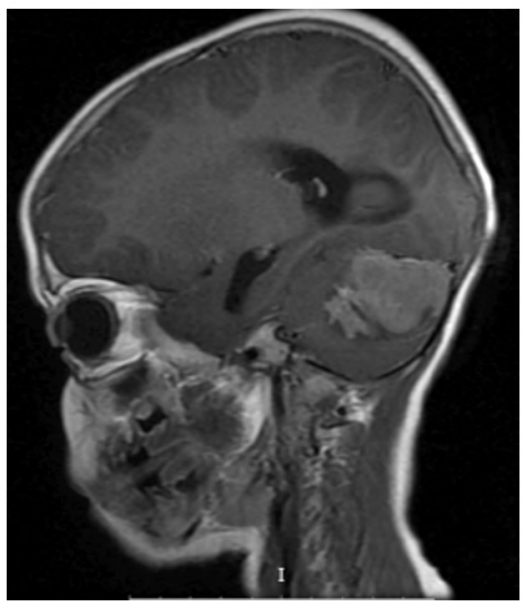

E- Axial T 1 WI+contrast.

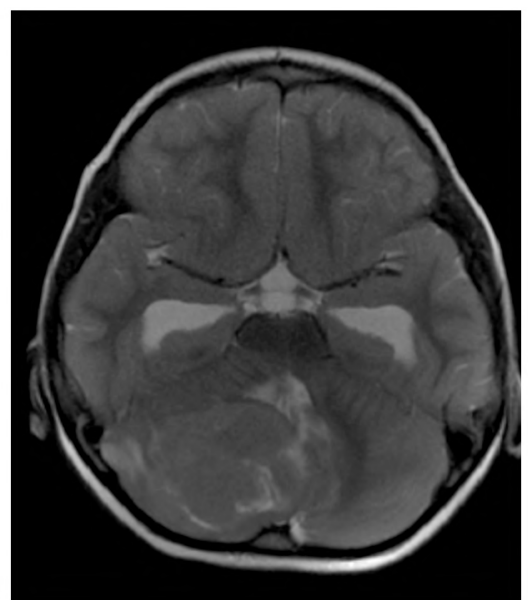

B- Axial T2WI.

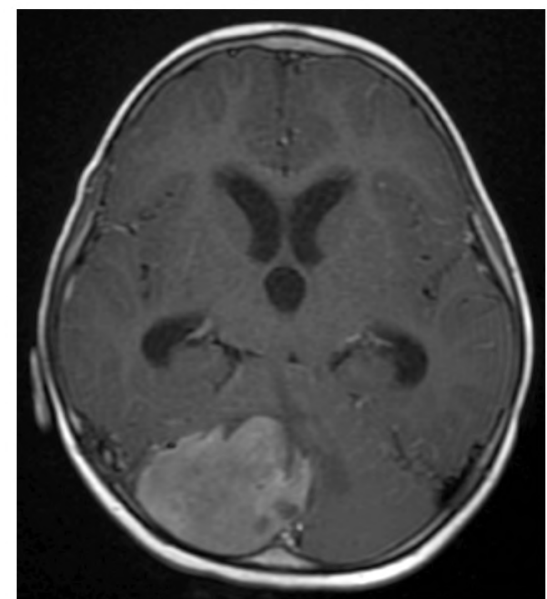

D- Axial T1+C.

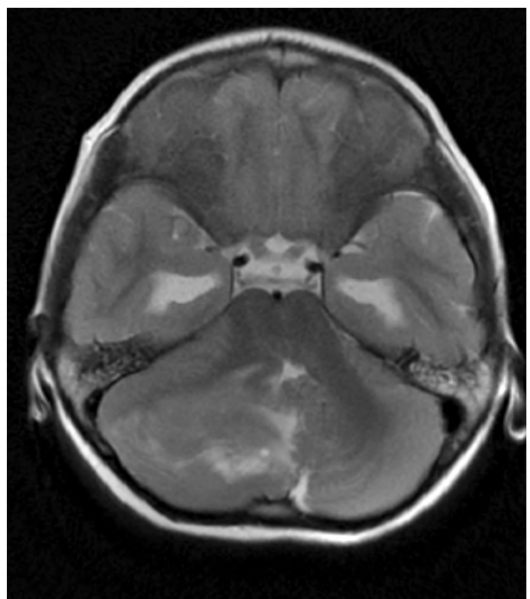

F- Axial T2.

Fig. (8): Female patient 4 years old complaining of persistant headache.

MRI: Abnormal space occupying lesion is seen at the right cerebellar hemisphere measures $4 \times 4.6 \mathrm{~cm}$ displaying low signal in T1WI (A), high signal in T2WI (B) \& FLAIR (C), intense homogenous enhancement after IV contrast injection (D)\&(E) surrounded by cystic parts displaying low signal in T1 WI and high signal in T2 WI (CSF like signal) (F) exerting mass effect in the form of compression of sulci and cistern and fourth ventricle causing supratentorial hydrocephalus in the form of dilated third and lateral ventricle picture is suggestive of medulloblastoma with supratentorial hydrocephalus.

$D W I$ : The lesion appeared with restricted diffusion. (I)

ADC values $(J): 0.8 \times 10^{-3} \mathrm{~mm}^{2} / \mathrm{s}$ with perilesional area ADC value measured $0.9 \times 10^{-3} \mathrm{~mm}^{2} / \mathrm{s}$

Histological examination: Revealed that the lesion is medulloblastoma. 


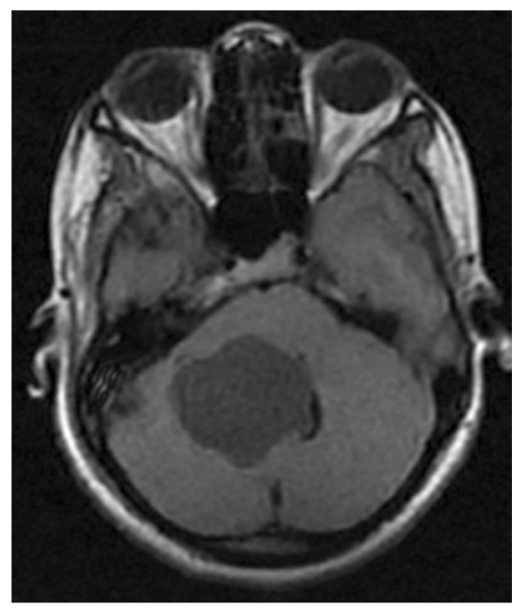

A- Axial T1WI.

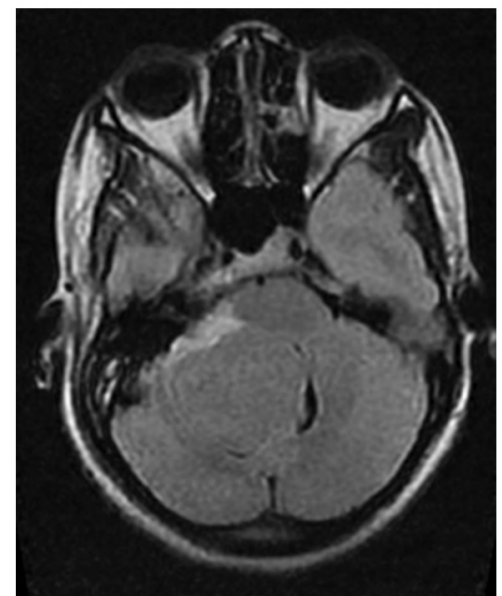

C- Axial FLAIR.

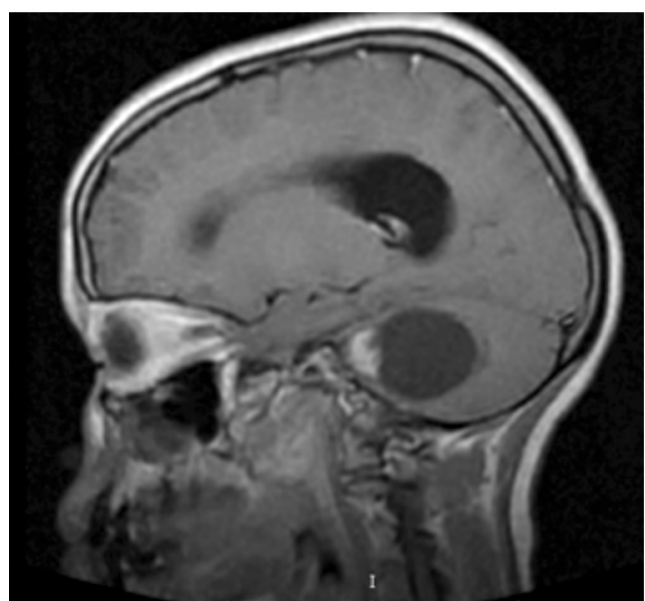

E- Sagittal T1WI+contrast.

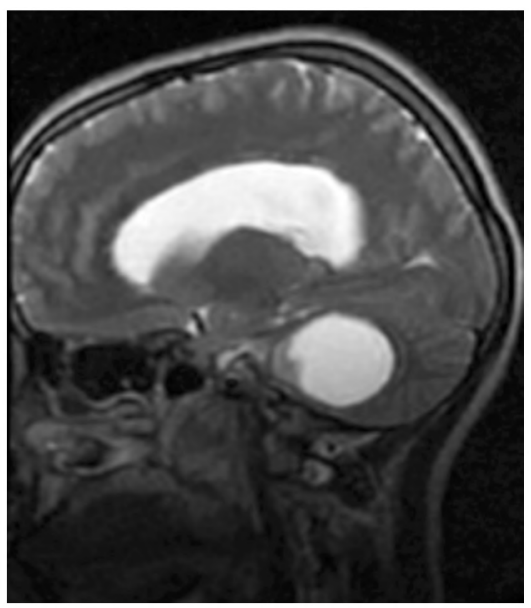

B- Sagittal T2WI.

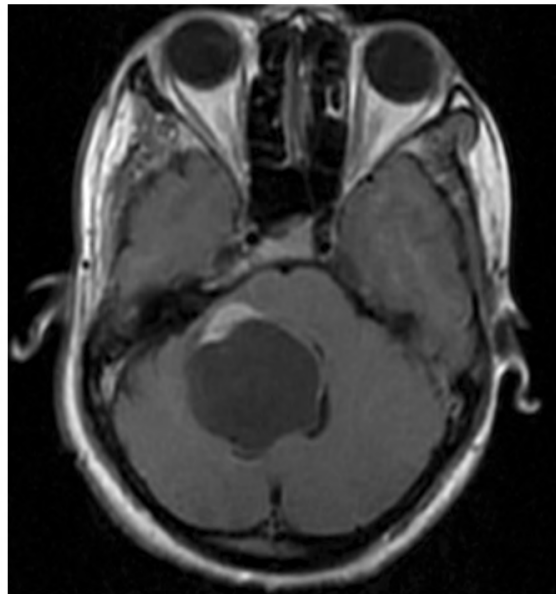

D- Axial T 1 WI+contrast.

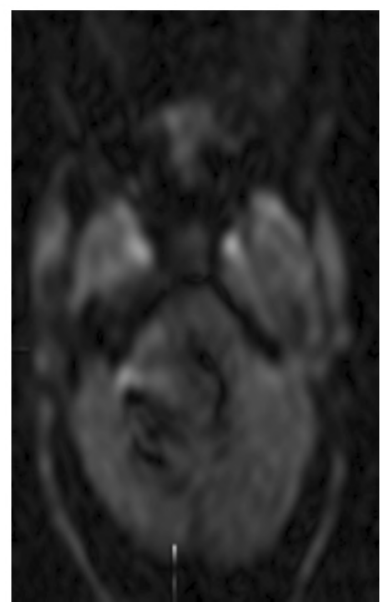

F- DWI

Fig. (9): Female patient aged 12 years complaining of headache and blurring of vision. Eman (pilocystic astrocytoma).

MRI: Large cystic mass with superficial solid mural nodule is seen in the posterior fossa centered upon the right cerebellar hemisphere, its solid part display isointense signal in T1 WI (A), hyperintense signal in T2 WI (B) and FLAIR (C), with bright enhancement after Gd administration (D) and (E), the mass exert mass effect in the form of compression of the fourth ventricle as well as pons and effacement of prepontine cistern associated with moderate dilatation of supratentorial ventricular system with trans ependymal retrograde CSF permeation.

$D W I$ : Free diffusion is seen in DWI.

ADC values: $1.2 \times 10^{-3} \mathrm{~mm}^{2} / \mathrm{s}(\mathrm{I})$.

The above MRI and DWI \& ADC picture: Are in favor of pilocytic astrocytoma. 


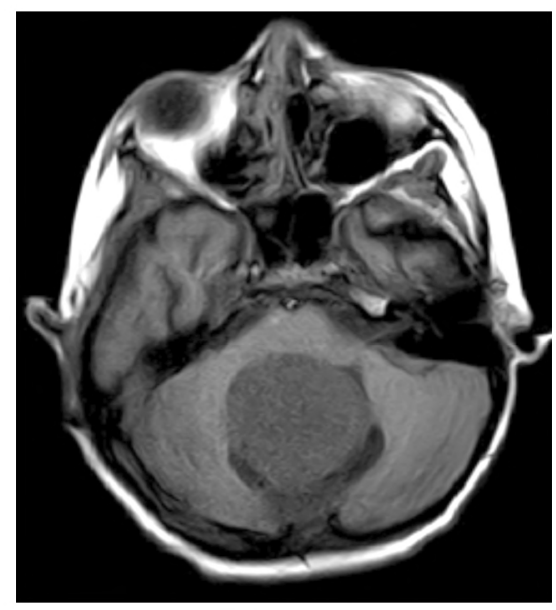

A- Axial T $1 \mathrm{WI}$

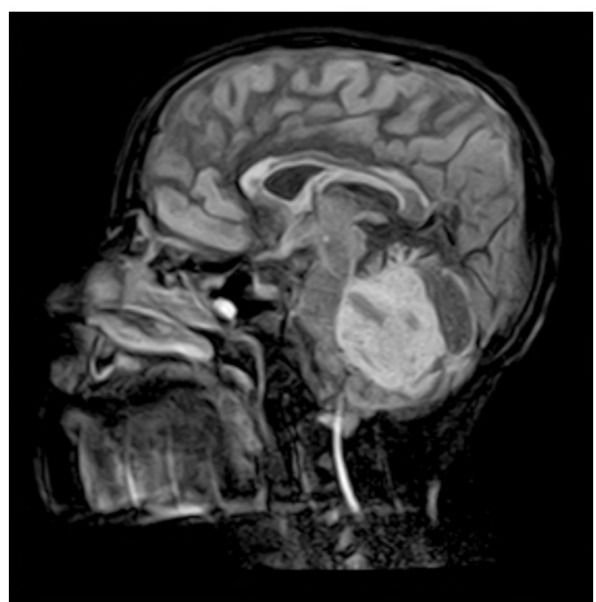

C- Sagittal FLAIR.

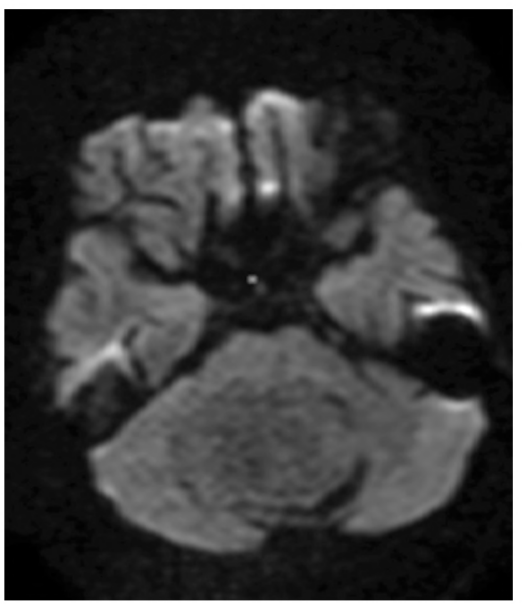

H- Diffusion WI.

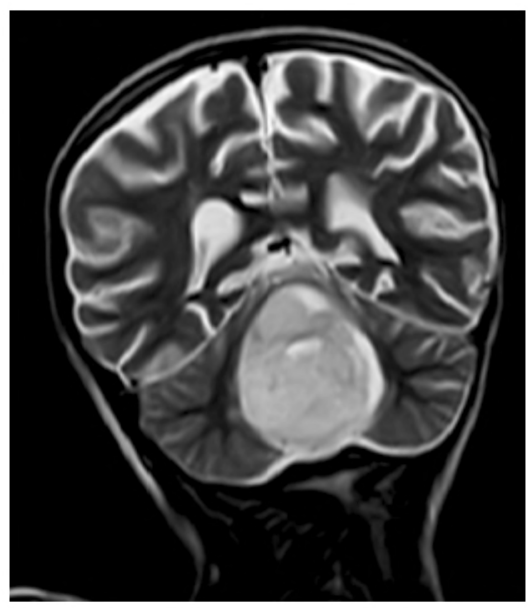

B- Coronal T2.

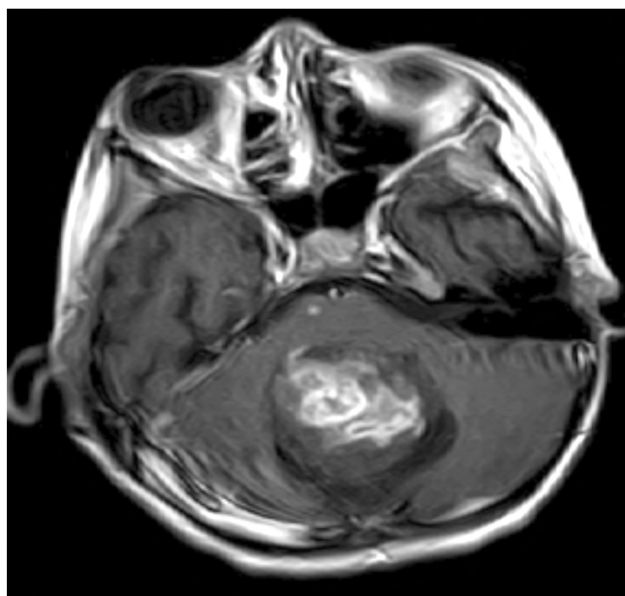

D- Axial T 1 WI+contrast.

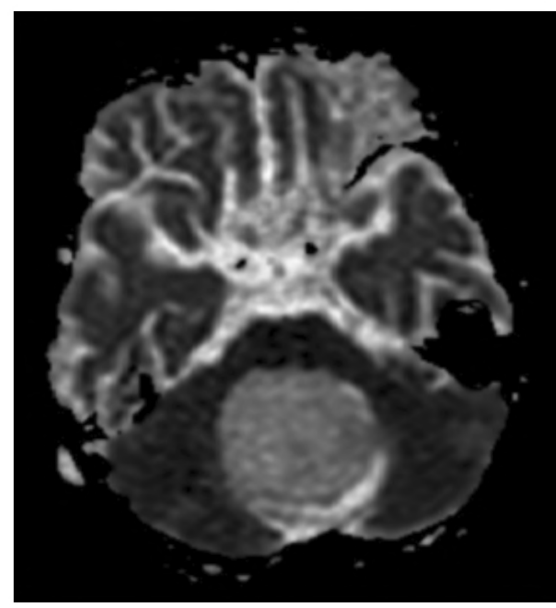

I- ADC image.

Fig. (10): Female patient aged 8 years old known to have cerebral palsy since birth.

MRI: Large posterior fossa mass is seen arising from the fourth ventricle measures $3 \times 3.5 \times 3.7 \mathrm{~cm}$ displaying low SI in T1 WI (A) and high SI in T2 WI (B) and FLAIR with central foci of signal heterogeneity representing necrosis (C), the mass show heterogeneous enhancement after IV contrast injection (D) with moderate dilatation of the fourth ventricle around the mass and supratentorial hydrocephalus.

$D W I$ : The lesion showed free diffusion $(\mathrm{H})$.

ADC values: $1.5 \times 10^{-3} \mathrm{~mm}^{2} / \mathrm{s}$ (I). 


\section{Discussion}

Conventional MRI is an essential tool for diagnosis and evaluation of posterior fossa tumours in pediatrics [9]. DW image helped in differentiating grades and types of pediatric brain tumours in the posterior fossa [10]. This study was encountered on forty cases, 24 male and 16 females, their age ranged from 2 to 10 years. The most common clinical presentation in our group of patients was headache and vomiting, which was in agreement with the study of LIN \& Riva [11].

According to conventional MRI findings, the most common pediatric posterior fossa tumors encountered in our study were medulloblastoma (16 cases), pilocytic astrocytoma in (8 cases), ependymoma in (8 cases), diffuse pontine glioma in (6 cases) and Schwannoma only in (2 cases), which disagree with Cascone et al., [2]

As regard the site from which the tumour arise, all cases of pilocytic astrocytoma were seen located near the mid line arising from cerebellum as wellcircumscribed, cystic like masses with a soft tissue mural nodule which was in agree with Kelly K. et al., [12], while in medulloblastoma 10 cases were located at cerebellar vermis and 6 cases located at cerebellar hemisphere which was in agree with Fruehwald-Pallamar et al., [13], in cases of glioma all cases were of diffuse pontine glioma which was in agree with Donaldson S., et al., [14]

The most common other MRI association was hydrocephalus which was present in 22 cases, 10 of them were medulloblastoma (55\%), the other findings were cystic changes present in 14 cases, 8 of them were juvenile pilocytic astrocytoma cases $(35 \%)$ and hemorrhage present in 8 cases, three of them were medulloblastoma (20\%), this was in agree with Reddy et al., [15].

The pattern of enhancement in our studied patients was, heterogeneous enhancement in 12 cases of medulloblastoma while the other four cases showed homogenous enhancement, this was in agree with Eran A. et al., [16]. In cases of Ependymoma, the eight cases showed heterogeneous enhancement, in JPA all solid nodules showed homogenous enhancement and in pontine glioma two cases showed heterogeneous enhancement, two cases, faint enhancement and the last, no enhancement, while in case of Schwannoma homogenous intense enhancement was seen, this was in agreement with Mauffrey [17].
As regards DWI \& ADC maps, there was a difference in ADC value between JPA and medulloblastoma. It was higher than $1.3 \times 10^{-3} \mathrm{~mm}^{2} / \mathrm{s}$ in JPA cases while in medulloblastoma, ranged between 0.55 and $0.9 \times 10^{-3} \mathrm{~mm}^{2} / \mathrm{s}$, (malignant lesion) which was in consistent with the study of Rumboldt et al., [18], as they concluded that significant differences in cellularity of pediatric cerebellar neoplasms, particularly between JPAs and medulloblastoma indicate that these lesions could potentially be distinguished by their ADC values, used cut off values of more than $1.4 \times 10^{-3} \mathrm{~mm}^{2} / \mathrm{s}$ for JPA and less than $0.9 \times 10^{-3} \mathrm{~mm}^{2} / \mathrm{s}$ for medulloblastoma.

In ependymoma, all cases showed heterogeneous signal in DWI and ADC map with ADC value ranging from 1.01 and $1.3 \times 10^{-3} \mathrm{~mm}^{2} / \mathrm{s}$ suggesting restricted diffusion more than that seen in JPA cases consistent with Yamasaki et al., [19].

In cases of pontine Glioma, it was hypointense on DWI compared to normal brain parenchyma denoting free diffusion, some cases showed heterogeneous signal intensity in DWI and ADC map denoting high grade of anaplesia with ADC value ranging from $1.1 \times 10^{-3}$ to $1.5 \times 10^{-3}$ which was consistent with the study of Lobel et al., [20].

In cases of Schwannoma, the signal intensity was hypointense on DWI and hyperintense on ADC map compared to normal parenchyma denoting free diffusion, with ADC value of $1.6 \times 10^{-3}$ which was in agreement with the study of with Beaman et al., [21].

From our results, Conventional MRI had successfully diagnosed 32 cases, 10 cases as medulloblastoma, 8 cases as juvenile pilocytic astrocytoma, 6 cases as glioma, 6 cases as ependymoma and 2 cases as Schwannoma. DWI \& ADC values had correctly diagnosed 16 cases as medulloblastoma, 8 cases as juvenile pilocytic astrocytoma, 8 cases as ependymoma, 6 cases as pontine glioma and 2 cases as Schwannoma.

By comparing MRI findings with histopathology it was found that conventional MRI combined with DWI and ADC values showed sensitivity of $94 \%$ which is statistically significant positive strong correlation between MRI diagnosis and Histopathological confirmation.

\section{Conclusion:}

Conventional MRI with DWI \& ADC has high accuracy in the differentiation of posterior fossa tumours in pediatrics. 


\section{References}

1- PLAZA M.J., BORJA M.J., ALTMAN N. and SAIGAL G.: Conventional and advanced MRI features of pediatric intracranial tumors: Posterior fossa and suprasellar tumors. AJR, 200 (5): 1115-24, 2013.

2- CASCONE D., PANICO M.R., BUONOCORE M.C., CICALA D., et al.: Neuroimaging of posterior fossa astrocytoma in children, Springer international publishing Switzerland, 354: 319-325, 2015.

3- WAGNER M.W., PORETTI A., HUISMAN T.A.G.M. and BOSEMANI T.: Conventional and advanced (DTI/SWI) neuroimaging findings in pediatric oligodendroglioma. Childs Nerv Syst, 31 (6): 885-891, 2015.

4- Yeom K.W., Mobley B.C., Lober R.M., Andre J.B., et al.: Distinctive MRI features of pediatric medulloblastoma subtypes. AJR, 200 (4): 895-903, 2013.

5- YUH E.L., BARKOVICH A.J. and GUPTA N.: Imaging of ependymoma MRI and CT, Childs Nerv Syst, 25: 12031213, 2009.

6- POUSSAINT T.Y., KOCAK M., VAJAPEYAM S., PACKER R.I., et al.: MRI as a central component of clinical trials analysis in brain stem gliomas: A report from pediatric brain tumor consortium (PBTC). Neuro Oncol., 13 (4): 417-427, 2011.

7- GAUDINO S., RUSSO R., VERDOLOTTI T., CAULO M., et al.: Advanced MR imaging in hemispheric low grade gliomas before surgery; the indications and limits in the pediatric age. Childs Nerv Syst, 32 (10): 1813$1822,2016$.

8- DAVIS F.G. and McCARTHY B.J.: Epidemiology of brain tumors, Curr. Opin. Neurol., 13: 635-640, 2000.

9- PROVENZALE J.M., MUKUNDAN S. and BARBORIAK D.P.: Diffusion weighted and perfusion MR imaging for brain tumor characterization and assessment of treatment response. International society of magnetic resonance imaging in Medicine, 239 (3): 632-649, 2006.

10- HUMPHRIES P.D., SEBIRE N.J., SIEGEL M.J. and OSLEN Ø.E.: Tumors in pediatric patients and diffusion weighted MR imaging: apparent diffusion coefficient and tumor cellularity. Radiology, 245: 848-854, 2007.
11- TA LIN C. and RIVA-CAMBRIN J.K.: Management of posterior fossa tumors and hydrocephalus in children: A review. Childs Nervous System, 31 (10): 1781-1789, 2015.

12- KOELLER K.K. and RUSHING E.J.: From the archives of the AFIP. Pilocytic Astrocytoma: Radiologic-pathologic correlation. Radiographics, 24: 1693-1708, 2004.

13- FRUEHWALD P.J., PUCHNER S.B., ROSSI A., GARRE M.L., et al.: Magnetic resonance imaging spectrum of medulloblastoma. Neuroradiology, 53 (6): 387-396, 2011.

14- DONALDSON S.S., LANINGHAM F. and FISHER P.G.: Advances towards understanding brain stem gliomas. Journal of Clinical Oncology, 24: 1266-1272, 2006.

15- LAM S., REDDY G., LIN Y. and JEA A.: Mangement of hydrocephalus in children with posterior fossa tumor. Surgical Neurology International, 6: 346-348, 2015.

16- ERAN A., OZTURK A., AYGUN N. and IZBUDAK I.: Medulloblastoma: Atypical CT and MRI findings in children, Pediatric Radiology Journal, 40 (7): 1254-1262, 2010.

17- MAUFFREY C.: Pediatric brain stem gliomas: Prognostic factors and management. Journal of Clinical Neuroscience, 13 (4): 431-437, 2006.

18- RUMBOLDT Z., CAMACHO D., LAKE D., WELSH C.T., et al.: Apparent diffusion coefficients for differnation of cerebellar tumors in children. American Journal of Neuroradiology, 27 (6): 1362-1369, 2006.

19- YAMASAKI F., KURISU K., SATOH K., ARITA K., et al.: Apparent diffusion coefficient of human brain tumors at MR imaging, Radiology, 235 (3): 985-991, 2005.

20- LOBEL U., SEDLACIK J., REDDICK W.E., KOCAK M., et al.: Quantitaive diffusion weighted and dynamic susceptibility weighted contrast enhanced perfusion MR imaging analysis of T2 hypointense lesion components in pediatric diffuse intrinsic glioma, American Journal of Neuroradiology, 32 (2): 315-322, 2011.

21- BEAMAN F.D., KRANSDORF M.J. and MENKE D.M.: Schwannoma: Radiologic-pathologic correlation. Radiographics, 24 (5): 1477-1481, 2004. 


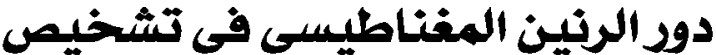

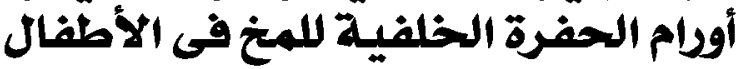

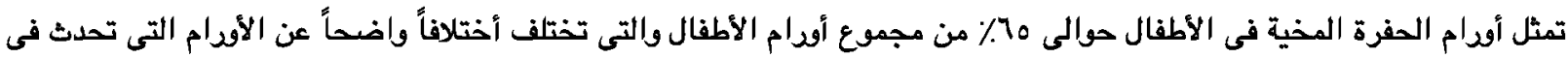

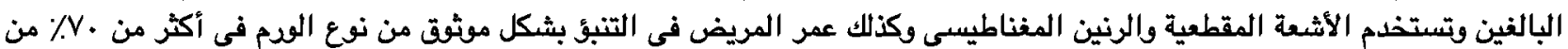

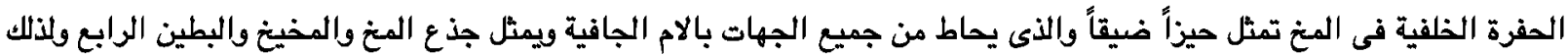

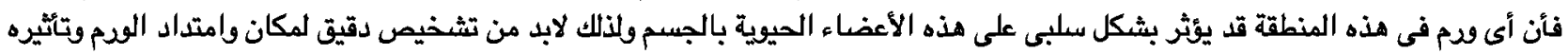

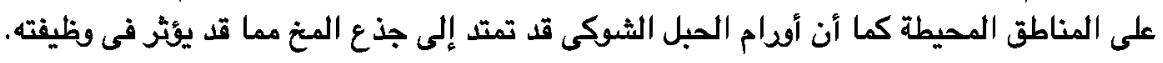

ولان الأشعة المقطعية لها بعض القيود فى تثخيص هذه الأودام والتى تتمثل في صعوبة تحديد المكان بدقة وتأثيره على المناطق المحيطة

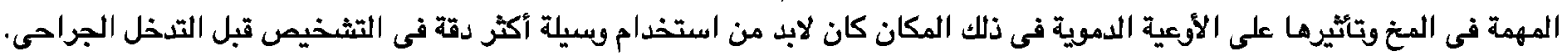
ولذا يستخدم الرنين المغناطيسى فى تشخيص أودام الحفرة الخلفية فى المخ وكذلك تحديد تأثيره على المناطق المحيطة ولكن قد يواجه

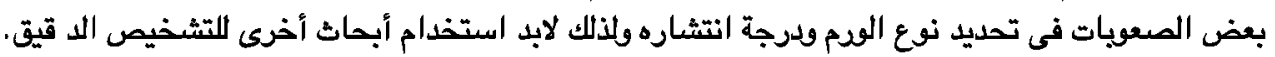

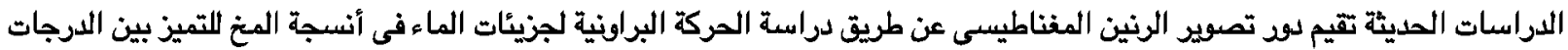

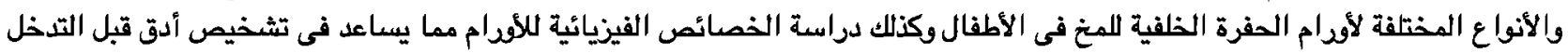

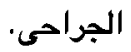

وقياس معامل الإنتشار الواضح وهو مقياس لعجم انتشار جزيئات الماء داخل الأنسجة يفيد فى توضيح نوع الودم وكمية الماء بداخله

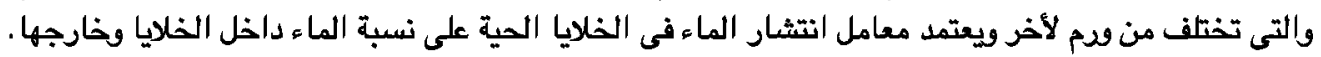

والهدف من هذه الدراسة هى بحث ودراسة دود الرنين المغناطيسى وحساب قيمة معا مل الانتشار الظاهرى فى تشخيص أودام الحفرة

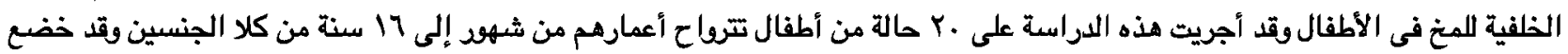

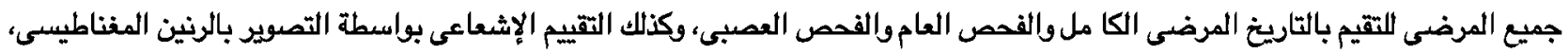
وتمت مقارنة نتائجهم مع التحليل النسيجى المرضى وصجدنا النتائج التالية:

ودم النخاع هو ودم الحفرة الخلفى الاكثر شيوعاً فى هذه الدراسة تليها إبنديموما ونجمى خلية نجمى فى حين كان الودم الصبييى ودم

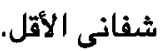

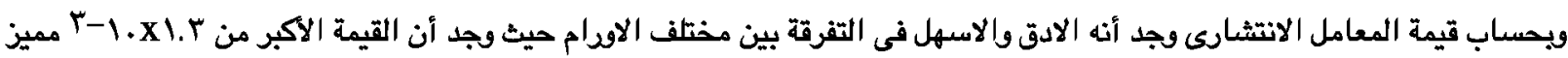

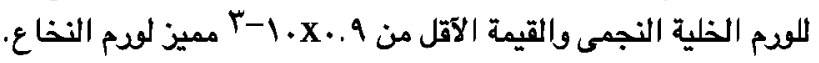

